\title{
Ship-wave induced sediment transport in tidal creeks
}

\author{
T. M. Ravens \& R. Thomas \\ Department of Maritime Systems Engineering, \\ Texas A\&M University at Galveston, Galveston, Texas, USA
}

\begin{abstract}
During the summer of 2005, a tidal creek ("Pine Gully") within a few km of the Houston Ship Channel (USA) was totally plugged up with a 200-m long and $1.5-\mathrm{m}$ deep plug of silt and fine sand. The volume of the plug was about 1,800 cubic meters. The seaward end of the plug was about $200 \mathrm{~m}$ landward of the creek's inlet. Between November 2005 and January 2006, several hours of measurements of velocity, pressure, and suspended sediment concentration were taken in the creek about half way between the plug and the inlet. Field observations and analysis of these data indicated ship-wave-induced surges of water. These surges caused a net transport of about 0.44 cubic meters per ship of suspended silt and fine sand toward the plug. This transport rate was sufficient to explain the observed rate of accumulation of sediment in the plug over a 5month period. Cores of the plug indicated that the plug material (fine sand and silt) was consistent throughout, suggesting a single pathway (from the bay). During the period of plug formation, rainfall and creek discharge were relatively low indicating a likely factor for the plugging.

Keywords: tidal creek siltation, ship-wave induced bores.
\end{abstract}

\section{Introduction}

Between May and August of 2005, a plug of fine sand and silt formed in Pine Gully, a 3 km-long tidal creek by Houston Ship Channel in northwest Galveston Bay (Figure 1). The plug completely blocked the flow of water from the watershed, raising concerns about possible flooding. The seaward end of the plug is about $300 \mathrm{~m}$ from the Pine Gully inlet (Figure 2) and the plug extends about $200 \mathrm{~m}$. The plug also filled about $100 \mathrm{~m}$ of a tributary to the Pine Gully 
(Figure 1). The plug was 1 to $1.5 \mathrm{~m}$ thick and the total volume of the plug was about 1,800 cubic meters.

The Pine Gully drains an 850 hectare watershed consisting of several residential subdivisions. At the time of the plug build up (between March and August 2005), a near-shore dredging project was underway south of the mouth of the Bayport Terminal (Figure 1). About 100,000 cubic meters was dredged from a rectangular template to a depth of about $6 \mathrm{~m}$. Geotechnical information provided by the Port of Houston shows that the material within the dredging site contained loose to medium dense grey, dark grey and brown silty sands from the surface to a depth of approximately $2.5 \mathrm{~m}$. Below that depth, the material was identified as stiff to very stiff brown clay.

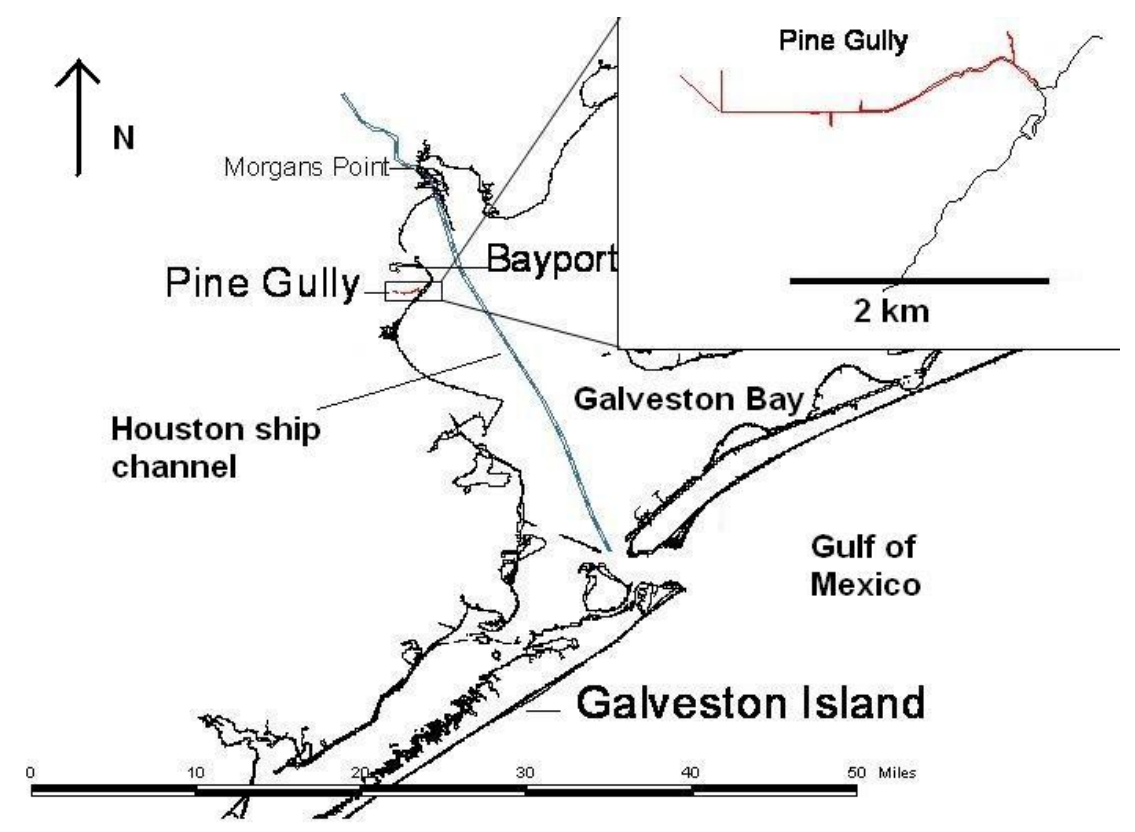

Figure 1: Location of the Pine Gully in Galveston Bay, Texas.

The formation of the plug raised a number of questions including:

(1) Did the material originate from the land or from the bay?

(2) Was the plug related to dredging activities on the bay?

(3) Was it related to the relatively low amounts of rainfall?

Was it related to ship waves which appeared to be the cause of strong bores that propagated up the creek (Figure 2)? 


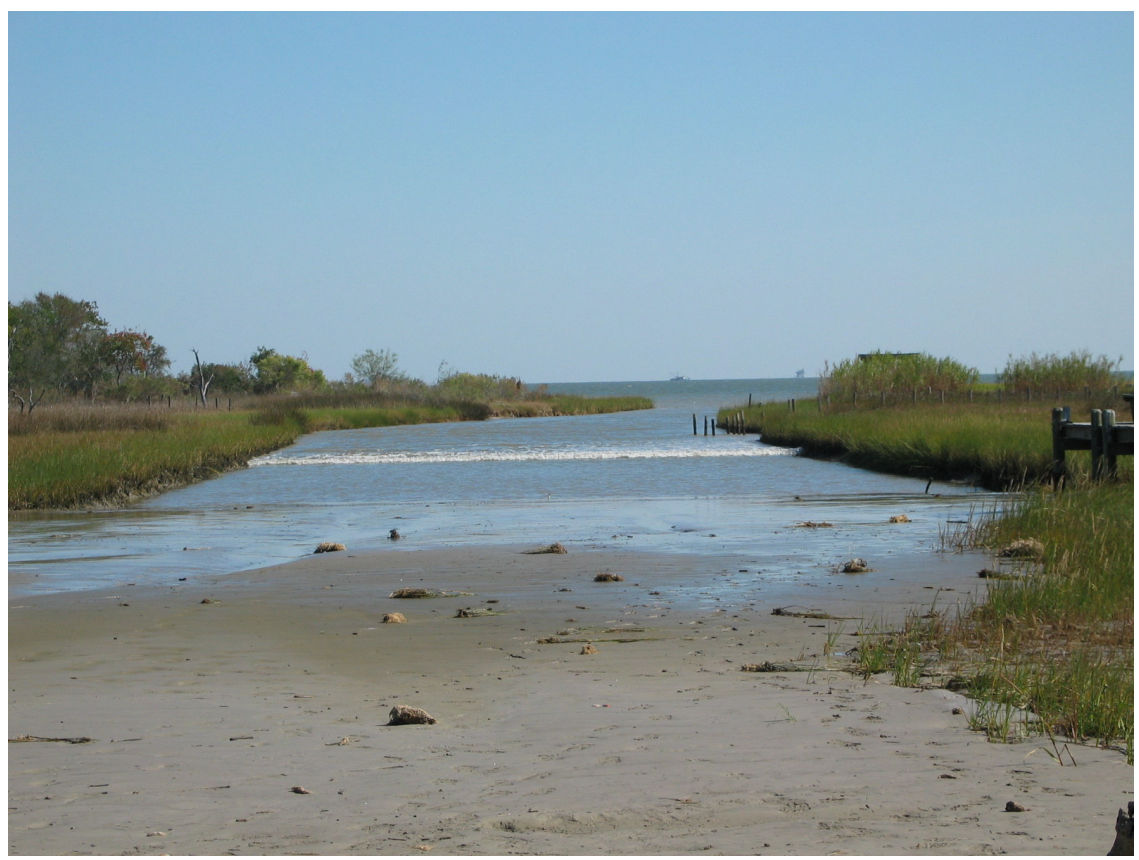

Figure 2: View of the Pine Gully Inlet and a small bore from the plug on $11 / 15 / 2005$.

\section{The role of ship-wave-induced bores}

Preliminary site visits indicated that ship-wave-induced bores were the dominant hydrodynamic and sediment transport phenomena taking place in the Gully seaward of the plug (when there was no rainfall). In order to quantify the role of these bores, velocity, pressure, and suspended particle measurements were made in three deployments in the Gully halfway between the plug and the entrance (on Nov. 5, 2005, Dec. 22, 2005, and Jan. 5, 2006). Velocity was measured at $1 \mathrm{~Hz}$, $13 \mathrm{~cm}$ above bottom using an acoustic Doppler velocimeter (ADV, Nortek, Norway). Suspended particle concentration was measured at 15 and $24 \mathrm{~cm}$ above bottom using an optical backscatter sensor (OBS-3, D\&A Instrument Co., Washington, USA). Water samples were collected at regular intervals throughout the deployments in order to calibrate the OBS's. Ship-wave generated bores were clearly evident in all the data collected.

Two ship-wave induced bores are evident in the data at 14.1 and 14.30 hours collected on Nov. 5, 2005 (Figure 3). Typically, at the time of the arrival of a bore, the water velocity and the suspended sediment concentration was relatively low. The bore caused a rapid increase in velocity (to about $1 \mathrm{~m} / \mathrm{s}$ ) and an instantaneous jump in water elevation. In the water behind the bore, the suspended sediment concentration increased to a maximum in about 1 minute. As expected, the sediment concentration increase was recorded sooner and 
occurred faster at the lower OBS relative to the upper one. This suggested local sediment resuspension rather than sediment advection. The suspended sediment was well-sorted fine sand and silt ( $\mathrm{d}_{50} \sim 60$ microns), with about $90 \%$ of the particle mass between 38 and 90 microns. The suspended sediment grain size distribution was comparable to that of the sediments in the plug, in the creek bed, and in the beach by the Gully inlet. The sediment bed consisted of $1 \mathrm{~cm}$ high ripples. The ripple crest-to-crest length was about $10 \mathrm{~cm}$.

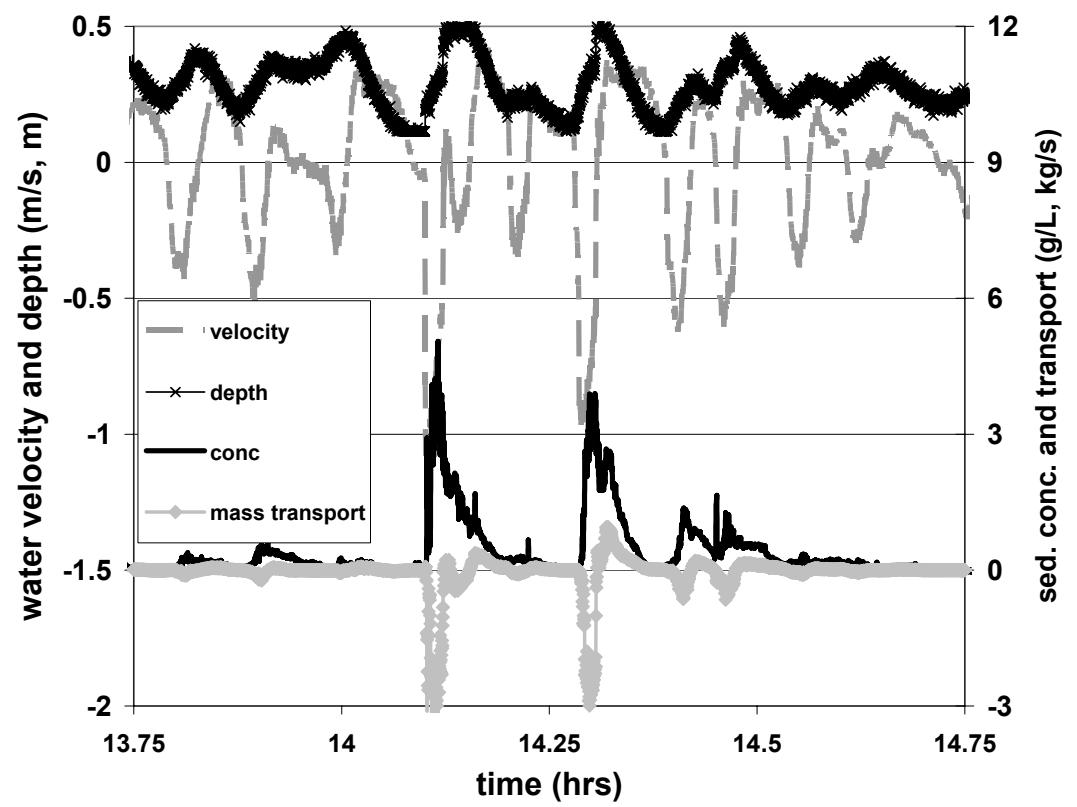

Figure 3: Water velocity (13 $\mathrm{cm}$ above bottom), depth, suspended sediment concentration (15 cm above bottom) and sediment transport during a 1 hour period on Nov. 5, 2005.

The suspended sediment transport rate (per unit width of creek), $q_{s}\left[\mathrm{~g} \mathrm{~m}^{-1} \mathrm{~s}^{-1}\right]$, was determined based on a vertical integration of the product of the sediment concentration $\left(\mathrm{c}(\mathrm{z}), \mathrm{g} \mathrm{m}^{-3}\right)$ and the longitudinal velocity $(\mathrm{u}(\mathrm{z}), \mathrm{m} / \mathrm{s})$ :

$$
q_{s}=\int u(z) c(z) d z
$$

The total mass transport (g/s) was obtained by multiplying $q_{s}$ by $15 \mathrm{~m}$, the width of the Pine Gully at the point of measurement. The vertical velocity distribution was calculated based on the measured velocity at $0.13 \mathrm{~m}$ above bottom and based on observed bottom roughness (r) associated with the sand ripple height ( $\mathrm{r}$ $\sim 0.01 \mathrm{~m}$ ). A logarithmic velocity profile was assumed: 


$$
u(z)=\frac{u_{*}}{\kappa} \ln \left(\frac{z}{z_{o}}\right)
$$

where $u_{*}$ is the friction velocity $\left(u_{*}=\sqrt{\tau_{o} / \rho}\right), \tau_{0}$ is the bottom stress, $\rho$ is the water density, $\kappa$ is the von Karmen constant $(\sim 0.4)$, $\mathrm{z}$ is the vertical position $(\mathrm{m})$, $\mathrm{z}_{\mathrm{o}}$ is the roughness length $(\sim \mathrm{r} / 30)$ for rough turbulent flow, and $\mathrm{r}$ is the equivalent Nikuradse roughness assumed to be equal to the ripple height (Nielsen [1]). The friction velocity was obtained based on the measured velocity (and $z_{\mathrm{o}}$ ).

Sediment concentration was determined based on turbidity measurements made with the OBS's which had been calibrated by measuring sediment concentration in a number of water samples. The sediment distribution was obtained based on the Rouse equation (Yang [2]):

$$
C(z)=C_{a}\left(\frac{z\left(h-z_{a}\right)}{z_{a}(h-z)}\right)^{\frac{-w_{o}}{\kappa u_{*}}}
$$

where $C_{a}$ is the reference concentration (taken here to be the measured concentration at $\mathrm{z}=0.13 \mathrm{~m}), \mathrm{h}$ is the water depth, $\mathrm{z}_{\mathrm{a}}$ is the vertical position associated with the reference concentration $(0.13 \mathrm{~m})$, and $\mathrm{w}_{\mathrm{o}}$ is the sediment fall velocity calculated according to Stokes Law (Nielsen [1]).

During the three hour deployment on Nov. 5 2005, four ship-wave-induced surges (including the two shown in Figure 4) were analyzed. On average, the onshore suspended sediment transport was $0.54 \mathrm{~kg}$ per $\mathrm{m}$ width per second. Considering the $15 \mathrm{~m}$ width of the gully at the point of measurement, the average sediment transport per ship wave was $0.38 \mathrm{~m}^{3}$ per ship (assuming a porosity of 0.4, Table 1).

Bedload transport was calculated based on the empirical Meyer Peter Muller formula (Nielsen [1]):

$$
\Phi=8\left(\Psi-\Psi_{c}\right)^{1.5}
$$

where $\Phi=\frac{Q_{b}}{d \sqrt{(s-1) g d}}$ is the dimensionless transport rate,

$Q_{b}$, is the dimensional transport rate $\left(\mathrm{m}^{2} \mathrm{~s}^{-1}\right)$,

$\mathrm{d}$ is the median sediment grain size $(\mathrm{m})$,

$\mathrm{s}$ is the ratio of sediment to water density (2.6),

$\mathrm{g}$ is the acceleration due to gravity,

$\Psi=\frac{\tau_{o}^{\prime}}{(s-1) \rho g d}$ is the Shields Parameter,

$\Psi=0.1$ is the critical Shields Parameter,

$\tau_{\mathrm{o}}^{\prime}$ is the skin friction stress $(\mathrm{Pa})$, and

$\rho$ is the water density, $\left(\mathrm{kg} \mathrm{m}^{-3}\right)$. 
The skin friction stress is the stress that the flowing water applies on the individual sediment grains. The roughness length for the skin friction calculation is the sediment $d_{90}$ (about 90 microns). Calculations indicate that bedload due to ship waves is on the order of $15 \%$ of the suspended load. The relatively small role for bedload is consistent with the results of Yang [2] and Julien [3] who report that the bedload is relatively small when the ratio of friction velocity to fall velocity is greater than 5 (as it is in our case). Table 1 summarizes the measured suspended sediment mass transport and the calculated bedload transport due to the four ship-wave-induced bores. It also reports the total amount of sediment transport during the 3-hour period. These calculations indicate the ship waves are the dominant sediment transport mechanism during this time period. They also suggest that there is a significant non-ship transport out of the inlet. Some of the apparent out-of-the-inlet transport is due to reflected ship waves (Figure 3). Wave reflection was enhanced due to the strong reflective character of the plug at the time of the measurements.

Table 1: Observed sediment transport in Pine Gully due to 4 ship-wave-induced bores between 12:43 and 15:38, Nov. 5, 2005.

\begin{tabular}{|l|l|l|l|}
\hline Event type & Time (hours) & $\begin{array}{l}\text { Suspended } \\
\text { sediment } \\
\text { transport } \\
(\mathrm{kg})\end{array}$ & $\begin{array}{l}\text { Bedload } \\
\text { transport }\end{array}$ \\
$(\mathrm{kg})$
\end{tabular}

During the second and third deployments on Dec. 222005 and on Jan. 5, 2006, ship-wave-induced sediment transport was again evident. On these two occasions, however, the water depth in the Pine Gully was significantly less (h $20 \mathrm{~cm}$ ). Preliminary calculations indicate that the mass transport due to ship waves was reduced by about $50 \%$, probably as a consequence of the reduced water depth, Hence, mass transport appears to be significantly affected by water depth. Considering yearly averaged water level data from a nearby tidal gage at Morgans Point (Figure 1), the November 5, 2005 water level and ship-wave induced mass transport ( $690 \mathrm{~kg}$ or $0.44 \mathrm{~m}^{3}$ per ship) is representative of average conditions. Shipping records indicate that about 10,000 ships per year pass through the Houston ship channel. Assuming a total sediment transport of 0.44 $\mathrm{m}^{3}$ per ship, about $4400 \mathrm{~m}^{3}$ of sediment might be transported into Pine Gully annually. The calculated volume of the plug $\left(1800 \mathrm{~m}^{3}\right)$ could be transported in about 5 months. 


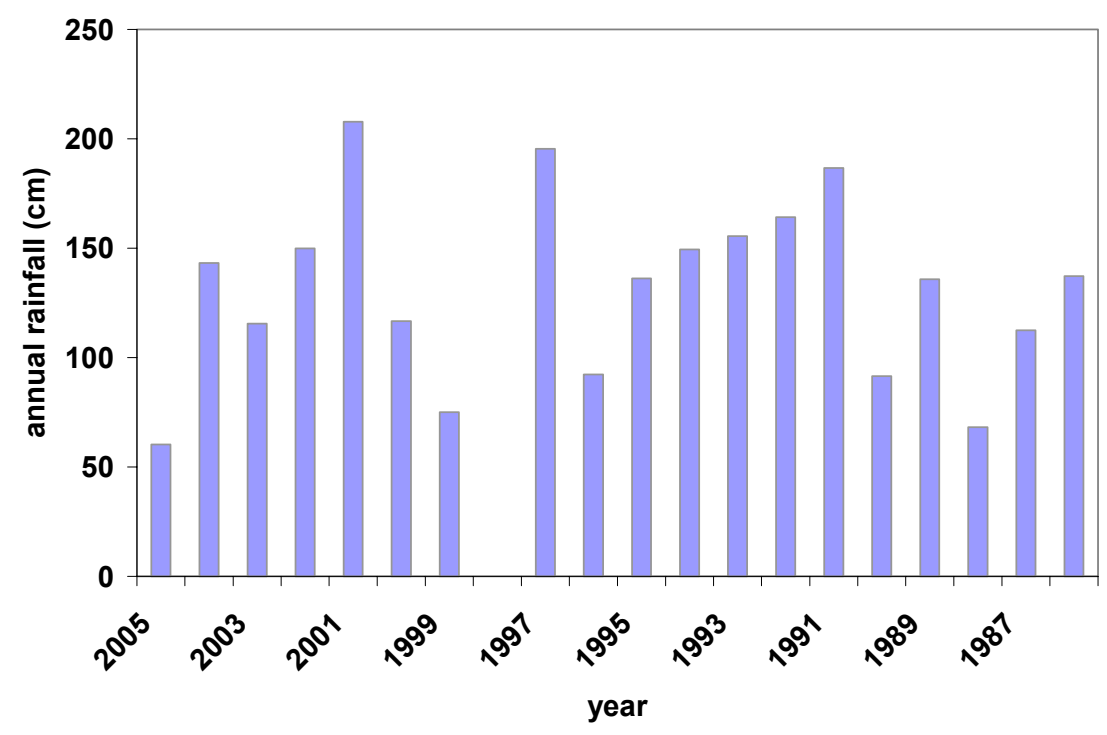

Figure 4: Annual rainfall in the vicinity of Pine Gully (1986-2005).

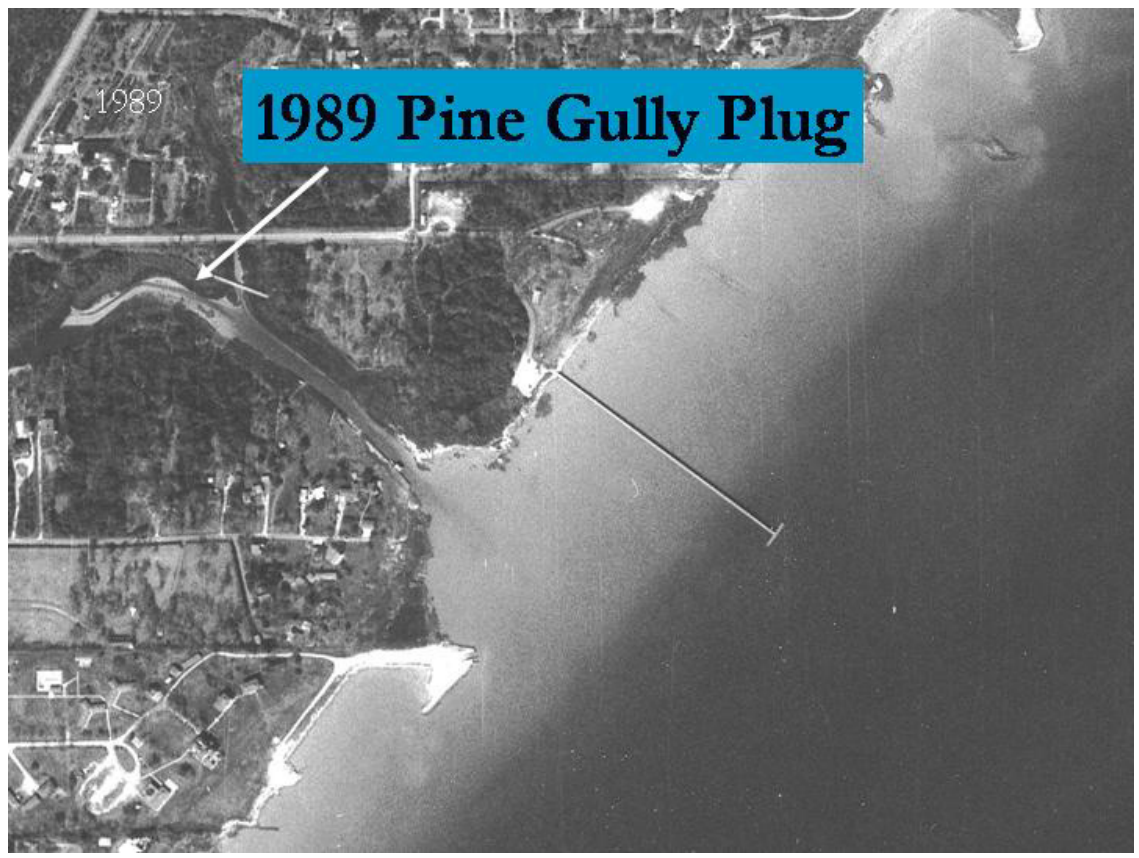

Figure 5: 1989 aerial photo of Pine Gully showing plug. 


\section{The role of rainfall-induced discharge from Pine Gully}

Examination of rainfall data indicates that the rainfall plays an important role in the sediment dynamics at Pine Gully. Rainfall leads to discharge which can transport sediments from the Gully into the bay. For example, hydrologic modeling of the watershed indicates that a rainfall event, with a two year recurrence interval, will generate a peak flow of $10 \mathrm{~m}^{3} / \mathrm{s}$, with velocity in the vicinity of the plug on the order of 1 to $2 \mathrm{~m} / \mathrm{s}$. A more moderate, $2 \mathrm{~cm}$, rainfall event on Nov. 15, 2005 cut a $30 \mathrm{~cm}$ deep and 2-m wide channel through the plug. Hence, there is significant sediment transport capacity due to rainfall. The importance of rainfall is evident when we examine the relationship between historic rainfall data (Figure 4) and the occurrence of Pine Gully sedimentation. In addition to the 2005 plugging, historic aerial photos indicates significant plug formation in 1989 (Figure 5). Both of these siltation events followed or were coincident with low annual rainfall (Figure 4).

\section{Concluding discussion}

The data presented here demonstrates that ship-wave-induced sediment transport can be an important sediment transport mechanism for shallow inlets in the vicinity of ship traffic. It also demonstrates the importance of rainfall-induced discharge in preventing siltation in inlets where tidal forces are insufficient. Calculations indicate that the tidal flow would be on the order of $0.07 \mathrm{~m} / \mathrm{s}$ in the unplugged channel.

The evidence suggests that the sediments originate from the bay. However, the role of the dredging project in providing a source for the sediments is uncertain. The beach adjacent to the Pine Gully inlet is shallow with a gradual slope. Wind waves break on the beach resuspending a significant concentration of sediment (e.g., $0.5 \mathrm{~g} / \mathrm{L}$ ) even under relatively mild conditions. This suggests that there is a large, ready source of sediment to be picked up and carried by ship-wave-induced surges. It appears that the ship-wave induced mass transport will occur whether or not there is additional sediment from a nearby dredging project.

\section{References}

[1] Nielsen, P., Coastal Bottom Boundary Layers and Sediment Transport, World Scientific: New Jersey, 1992.

[2] Yang, C. T., Sediment Transport Theory and Practice, McGraw Hill: New York, p. 161, 1996.

[3] Julien, P. Y. River Mechanics, Cambridge University Press: United Kingdom, p. 113, 2002. 